\title{
The effectiveness of agrotextile cover with organic photoluminophore in rooting cuttings of Hungarian lilac (Syringa josikaea J. Jacq. ex Rchb.)
}

\author{
Robert Khramov ${ }^{1}$, Natalia Martynova, ${ }^{2,}$, Natalia Besschetnova ${ }^{2}$, and Vladimir \\ Besschetnov $^{2}$, and Yuriy Luponosov ${ }^{3,4}$ \\ ${ }^{1}$ Institute of Theoretical and Experimental Biophysics of the Russian Academy of Sciences, 142290 \\ Pushchino, Russia \\ ${ }^{2}$ Nizhny Novgorod State Agricultural Academy, 603107 Nizhny Novgorod, Russia \\ ${ }^{3}$ Enikolopov Institute of Synthetic Polymeric Materials of the Russian Academy of Sciences, \\ Moscow, 117393, Russia \\ ${ }^{4}$ Moscow State University, Chemistry Department, 1/3 Leninskie Gory, Moscow, 119991, Russia
}

\begin{abstract}
The effectiveness of the use of a light-transforming shelter of vegetation structures consisting of a polypropylene spunbond with an organic photoluminophore integrated into its structure during the rooting of physiologically active stem cuttings of Hungarian lilac was studied. The object of the study was reproductively mature Hungarian lilac plants located in the arboretum of the Nizhny Novgorod State Agricultural Academy with geographical coordinates $56^{\circ} 14^{\prime} 32.7^{\prime \prime} \mathrm{N} 43^{\circ} 57^{\prime} 20.7^{\prime \prime E}$. The unequal reaction of the tested samples of Hungarian lilac to the use of luminophore in the shelters of vegetation structures during the rooting of cuttings was established, which manifested itself in all characteristics of regeneration processes. High rates of callus formation were in the shelter variants with a higher concentration of luminophore: $73.16 \pm 5.95 \%$ and $65.25 \pm 4.80 \%$. Lower than in other shelters, the result was recorded in the variant with the lowest luminophore density: $47.00 \pm 3.62 \%$.
\end{abstract}

\section{Introduction}

The active introduction of woody and shrubby plants into the composition of landscaping facilities and depositing carbon polygons requires the mobilization of a variety of technologies for replicating planting material, including rooting cuttings in vegetation structures $[1,2]$. The effectiveness of greenhouse farms is largely determined by the technical properties and optical characteristics of synthetic coatings used in their creation $[3,4]$. The use of light-transforming and light-correcting films and plastics for these purposes makes it possible to regulate the spectral and other parameters of the luminous flux in quantitative and qualitative terms $[4,5]$. When at the same time, the influence of the parameters of the luminous flux on vital processes in plant organisms is being discussed

\footnotetext{
*Corresponding author: martynova-natasha94@yandex.ru
} 
quite actively [6-9]. Hungarian lilac (Syringa josikaea J. Jacq. ex Rchb.) undoubtedly belongs to the number of plants that successfully perform sanitary-hygienic, decorativeaesthetic and recreational-balneological functions, [10]. The purpose of the research is to evaluate the effectiveness of using a light-transforming shelter of vegetation structures consisting of a spunbond with a photoluminophore integrated into its structure when rooting physiologically active stem cuttings of Hungarian lilac.

\section{Materials and methods}

The object of the study was reproductively mature Hungarian lilac plants located in the arboretum of the Nizhny Novgorod State Agricultural Academy with geographical coordinates $56^{\circ} 14^{\prime} 32.7^{\prime \prime} \mathrm{N} 43^{\circ} 57^{\prime} 20.7^{\prime \prime} \mathrm{E}$ and a height above sea level of $178 \mathrm{~m}$. Stem cuttings were simultaneously separated from the peripheral zone of the middle tier of a well-lit section of the crown of plants. They were planted according to uniform placement schemes $(5 \times 10 \mathrm{~cm})$ in vegetation structures identical in design and metric parameters. The number of cuttings in each variant is 40 pcs. Environmental parameters were monitored using an automatic METEOSCAN PRO 929 RST02929 weather station. Illumination conditions were recorded under cover and without it using a TKA-PKM 08 luxmeter. Light-transforming agrotextile was used as covering materials: polypropylene nonwoven spunbond $30 \pm 3 \mathrm{~g} / \mathrm{m} 2$, coated with polylactide varnish containing a new organic photoluminophore (PL) with different concentrations with absorption mainly in the 460$560 \mathrm{~nm}$ band, and re-emitting with a spectral maximum of $660 \mathrm{~nm}$ with a half-width of the spectrum of $610-730 \mathrm{~nm}$. Fluorescent molecules of the donor-acceptor type based on triphenylamine with effective radiation in the red range were used as PL $[11,12]$. Mass concentration of PL in the spunbond was varied: $0.25 \%$ (background 1); $0.10 \%$ (background 2); $0.05 \%$ (background 3) $0.025 \%$ (background 4). In addition, a variant of the spunbond having $10 \mathrm{~cm}$ wide alternating strips uncovered / covered with PL (concentration of $0.25 \%$ ) (background 5) was introduced into the scheme of the experiment. To assess the potential impact on the regeneration processes occurring on the lower cut of cuttings, a shelter made of the same spunbond with a lacquer film applied without luminophore (standard) was tested. The control was an unmodified shelter - polypropylene nonwoven spunbond (control). It was a non-woven thermally bonded polypropylene fabric with a density of $30 \mathrm{~g} / \mathrm{m}^{2}$. The effect of the optical characteristics of the covering material was tested by the reaction to its use of regeneration indicators according to the following signs: sign 1 - callus formation; sign 2 - the number of adnexal roots formed, pcs.; sign 3 - the length of the leading root, cm; sign 4 - the total total length of the adnexal roots, $\mathrm{cm}$; sign 5 - the total average length of the adnexal roots, cm; sign 6 - the total length of the lateral roots, $\mathrm{cm}$; sign 7 - the average length of the lateral roots, $\mathrm{cm}$; sign 8 - the proportion of the length of the leading root in the total length of the root system; sign 9 - the proportion of the length of the lateral roots in the total length of the root system; sign 10 - the ratio of the length of the leading root to the average length of the lateral roots; sign 11 is the ratio of the length of the leading root to the total average length of the roots; sign 12 - the height of the aboveground part of the stalk; sign 13 - the diameter of the root neck; sign 14 - the ratio of the height of the aboveground part of the stalk to the diameter of its root neck.

The statistical analysis was carried out taking into account the existing methods [13, 14]. Derived features were used, which is customary in forestry and biological studies [1521]. 


\section{Results and discussion}

The reaction of the tested samples of Hungarian lilac to the use of agrotextile with FL in the shelters of vegetation structures during rooting of cuttings was not the same, which was manifested in all characteristics of regeneration processes (Tables 1-4).

Cuttings showed a selective response to covering materials with different optical properties (see Table 1).

Table 1. Callusogenesis on cuttings of Hungarian lilac (\%)

\begin{tabular}{|l|c|c|c|c|c|c|c|c|c|}
\hline Variant & M & CKO & max. & min. & $\Delta_{\lim }$ & $\pm \mathrm{m}$ & $\mathrm{Cv}, \%$ & $\mathrm{t}$ & $\mathrm{P}, \%$ \\
\hline Background -1 & 73,16 & 36,62 & 100,00 & 10,00 & 90,00 & 5,94 & 50,06 & 12,31 & 8,12 \\
\hline Background -2 & 65,25 & 30,36 & 100,00 & 15,00 & 85,00 & 4,80 & 46,53 & 13,59 & 7,36 \\
\hline Background -3 & 53,50 & 39,26 & 100,00 & 10,00 & 90,00 & 6,21 & 73,38 & 8,62 & 11,60 \\
\hline Background -4 & 53,16 & 25,27 & 100,00 & 10,00 & 90,00 & 4,10 & 47,53 & 12,97 & 7,71 \\
\hline Background -5 & 47,00 & 22,89 & 100,00 & 20,00 & 80,00 & 3,62 & 48,71 & 12,98 & 7,70 \\
\hline Standard & 45,80 & 22,31 & 80,00 & 10,00 & 70,00 & 3,53 & 48,71 & 12,99 & 7,70 \\
\hline Control & 46,00 & 30,62 & 100,00 & 10,00 & 90,00 & 4,84 & 66,56 & 9,50 & 10,52 \\
\hline Total & 54,72 & 31,44 & 100,00 & 10,00 & 90,00 & 1,89 & 57,46 & 28,91 & 3,46 \\
\hline
\end{tabular}

${ }^{1}$ The values of indicators: $\mathrm{M}$ - arithmetic mean; SKO - standard deviation; max. - maximum value; min. - minimum value; $\Delta$ lim - range of values; $\pm \mathrm{m}$ - error of representativeness of the sample mean; $\mathrm{Cv}$, - coefficient of variation, \%; $\mathrm{t}$ - Student's criterion; $\mathrm{P}$ - accuracy of experience or relative error, $\%$.

The highest rates of callus formation were noted in the shelter variants with the highest concentration of luminophore: background $1-73.16 \pm 5.95 \%$ and background $2-65.25 \pm$ $4.80 \%$. Less than in the other tested shelters, the result was recorded in the variant with the lowest luminophore density: background $5-47.00 \pm 3.62 \%$. This is close to the results of the control variant $(46.00 \pm 4.84 \%)$ and the reference sample $(45.80 \pm 3.53 \%)$. The generalized value for all variants of the experiment was $54.72 \pm 1.89 \%$. In the variants with a light-transforming shelter, the best result exceeded the corresponding minimum by 1.56 times or by 26.15 percentage points.

The influence of lighting conditions on the activity of rhizogenesis on cuttings of Hungarian lilac (see Table. 2) caused, as in the previous case, an ambiguous response of the tested samples to the introduction of a light-transforming substance into the composition of the covering materials of different volumes.

Table 2. Number of adventitious roots on Hungarian lilac cuttings (pcs.)

\begin{tabular}{|l|c|c|c|c|c|c|c|c|c|}
\hline Variant & $\mathrm{M}$ & $\mathrm{CKO}$ & max. & min. & $\Delta_{\lim }$ & $\pm \mathrm{m}$ & $\mathrm{Cv}, \%$ & $\mathrm{t}$ & $\mathrm{P}, \%$ \\
\hline Background - & 12,89 & 5,93 & 22,00 & 2,00 & 20,00 & 0,96 & 45,96 & 13,41 & 7,46 \\
\hline Background -2 & 12,65 & 5,53 & 20,00 & 2,00 & 18,00 & 0,87 & 43,72 & 14,46 & 6,91 \\
\hline Background -3 & 10,85 & 4,70 & 21,00 & 5,00 & 16,00 & 0,74 & 43,31 & 14,60 & 6,85 \\
\hline Background -4 & 9,32 & 3,89 & 19,00 & 3,00 & 16,00 & 0,63 & 41,77 & 14,76 & 6,78 \\
\hline Background -5 & 9,50 & 3,21 & 15,00 & 3,00 & 12,00 & 0,51 & 33,80 & 18,71 & 5,34 \\
\hline Standard & 9,68 & 3,07 & 19,00 & 4,00 & 15,00 & 0,48 & 31,70 & 19,95 & 5,01 \\
\hline Control & 9,45 & 4,02 & 15,00 & 2,00 & 13,00 & 0,64 & 42,53 & 14,87 & 6,72 \\
\hline Total & 10,61 & 4,62 & 22,00 & 2,00 & 20,00 & 0,28 & 43,58 & 38,12 & 2,62 \\
\hline
\end{tabular}

The main trends in the nature of reactions to photoluminophore established for callus formation (see Table. 1), were preserved for this indicator (see Table 2). A greater number of subordinate roots arose in the case of shelters with increased luminophore density: background $1-12.89 \pm 0.96$ pcs. (background 1) and background $2-12.65 \pm 0.87$ pcs. (background 2). A smaller number of adventitious roots $(9.50 \pm 0.51$ pcs.) was formed in the variant with a reduced luminophore density (background 5). This ratio of estimates formed the excess of their maximum over the minimum by 1.38 times or by 3.58 pcs. 
Against the background of the generalized values for all variants of the experiment $(10.61 \pm$ 0.28 pcs.), the standard and control had noticeably smaller values: $9.68 \pm 0.48$ pcs. and 9.45 \pm 0.64 pcs., respectively. The best result in the variants with photoluminophore exceeded the control by 1.37 times or by 3.20 pcs., and the standard - by 1.33 times or by 3.22 pcs.

The growth rates of the leading root of the systems depended on the density of the luminophore applied to the surface of the greenhouse covering materials (see Table 3). Despite the fact that the indicators of most variants of the experiment differed little from the control $(8.54 \pm 0.58 \mathrm{~cm})$ and the standard $(8.57 \pm 0.41 \mathrm{~cm})$, the variant with an increased density of luminophore (background 1), having reached an estimate of $10.53 \pm 0.74 \mathrm{~cm}$, demonstrated a noticeable superiority over them: 1.23 times or $1.99 \mathrm{~cm}$ (relative to the control) and 1.23 twice or by $1.96 \mathrm{~cm}$ (relative to the standard). The generalized average value was $8.84 \pm 0.23 \mathrm{~cm}$.

Table 3. Length of the leading root on cuttings of Hungarian lilac $(\mathrm{cm})$

\begin{tabular}{|l|c|c|c|c|c|c|c|c|c|}
\hline Variant & $\mathrm{M}$ & $\mathrm{CKO}$ & $\mathrm{max}$. & $\mathrm{min}$. & $\Delta_{\lim }$ & $\pm \mathrm{m}$ & $\mathrm{Cv}, \%$ & $\mathrm{t}$ & $\mathrm{P}, \%$ \\
\hline Background -1 & 10,53 & 4,55 & 15,00 & 0,90 & 14,10 & 0,74 & 43,27 & 14,25 & 7,02 \\
\hline Background -2 & 8,62 & 3,80 & 13,00 & 0,80 & 12,20 & 0,60 & 44,10 & 14,34 & 6,97 \\
\hline Background -3 & 8,59 & 3,25 & 11,50 & 1,00 & 10,50 & 0,51 & 37,85 & 16,71 & 5,98 \\
\hline Background -4 & 8,25 & 3,32 & 13,50 & 1,30 & 12,20 & 0,54 & 40,17 & 15,35 & 6,52 \\
\hline Background -5 & 8,84 & 5,07 & 15,00 & 1,00 & 14,00 & 0,80 & 57,39 & 11,02 & 9,07 \\
\hline Standard & 8,57 & 2,59 & 11,00 & 0,10 & 10,90 & 0,41 & 30,22 & 20,93 & 4,78 \\
\hline Control & 8,54 & 3,69 & 13,50 & 0,40 & 13,10 & 0,58 & 43,22 & 14,63 & 6,83 \\
\hline Total & 8,84 & 3,85 & 15,00 & 0,10 & 14,90 & 0,23 & 43,56 & 38,13 & 2,62 \\
\hline
\end{tabular}

One of the most significant indicators of regeneration occurring on cuttings is the total length of root systems (see Table 4). There is clearly an increase in the growth of adventitious roots in variants in which covering materials containing a higher amount of luminophore were involved: $92.88 \pm 9.24 \mathrm{~cm}$ (background 1) and $90.53 \pm 9.09 \mathrm{~cm}$ (background 2).

Table 4. Total length of root systems on cuttings $(\mathrm{cm})$

\begin{tabular}{|l|c|c|c|c|c|c|c|c|c|}
\hline Variant & M & CKO & max. & min. & $\Delta_{\lim }$ & $\pm \mathrm{m}$ & $\mathrm{Cv}, \%$ & $\mathrm{t}$ & $\mathrm{P}, \%$ \\
\hline Background - & 92,88 & 56,95 & 177,00 & 1,90 & 175,10 & 9,24 & 61,31 & 10,05 & 9,95 \\
\hline Background -2 & 90,53 & 57,49 & 162,40 & 1,50 & 160,90 & 9,09 & 63,51 & 9,96 & 10,04 \\
\hline Background -3 & 65,81 & 38,48 & 136,90 & 2,20 & 134,70 & 6,08 & 58,47 & 10,82 & 9,24 \\
\hline Background -4 & 55,22 & 29,19 & 99,80 & 3,80 & 96,00 & 4,74 & 52,87 & 11,66 & 8,58 \\
\hline Background -5 & 54,70 & 37,97 & 130,50 & 2,50 & 128,00 & 6,00 & 69,42 & 9,11 & 10,98 \\
\hline Standard & 54,81 & 38,21 & 184,10 & 7,00 & 177,10 & 6,04 & 69,71 & 9,07 & 11,02 \\
\hline Control & 54,86 & 34,44 & 107,00 & 0,60 & 106,40 & 5,44 & 62,78 & 10,07 & 9,93 \\
\hline Total & 66,87 & 45,46 & 184,10 & 0,60 & 183,50 & 2,74 & 67,99 & 24,43 & 4,09 \\
\hline
\end{tabular}

To a lesser extent, the accessory roots grew in variants in which the luminophore concentration was lower: $55.22 \pm 4.74 \mathrm{~cm}$ (background 4) and $54.70 \pm 6.00 \mathrm{~cm}$ (background 5). These estimates were close to the control indicators $(54.86 \pm 5.44 \mathrm{~cm})$ and the standard $(54.81 \pm 6.04 \mathrm{~cm})$. The introduction of photoluminophore into the structure of the covering materials created a positive effect: the control and standard indicators were 1.69 times less than in the best version of the experiment, or $38.07 \mathrm{~cm}$ and $38.03 \mathrm{~cm}$, respectively.

The recorded differences manifested themselves against a leveled background of environmental conditions, which gave reason to recognize the effect of the optical properties of the covering materials used as the cause of their occurrence. Confirmation of this was obtained during the analysis of variance (Table 5). For a number of indicators of the regenerative ability of cuttings, the differences were significant - Fisher's experimental criteria significantly exceeded the corresponding limit values for a given number of degrees 
of freedom at both 5 percent and 1 percent significance levels, taking values from 2.85 (sign 10) to $6.38(\operatorname{sign} 4)$ and $6.84(\operatorname{sign} 6)$ at $\mathrm{F}_{05}=2.13$ and $\mathrm{F}_{01}=2.87$.

Table 5. The significance of the differences between the application options ${ }^{1}$

\begin{tabular}{|c|c|c|c|c|c|c|c|c|c|}
\hline \multirow{3}{*}{$\begin{array}{l}\text { Signs of } \\
\text { regenerative } \\
\text { ability }\end{array}$} & \multirow{3}{*}{$\mathrm{F}_{\text {оп }}$} & \multicolumn{6}{|c|}{ The share of the influence of the factor $\left(\mathrm{h}^{2} \pm \mathrm{Sh}^{2}\right)$} & \multirow{2}{*}{\multicolumn{2}{|c|}{$\begin{array}{l}\text { Criteria for } \\
\text { differences }\end{array}$}} \\
\hline & & \multicolumn{3}{|c|}{ by Plokhinsky } & \multicolumn{3}{|c|}{ by Snedekor } & & \\
\hline & & $\mathrm{h}^{2}$ & $\pm \mathrm{Sh}^{2}$ & $\mathrm{~F}_{\mathrm{h}}{ }^{2}$ & $\mathrm{~h}^{2}$ & $\pm \mathrm{Sh}^{2}$ & $\mathrm{Fh}^{2}$ & $\mathrm{HCP}_{05}$ & $\mathrm{D}_{05}$ \\
\hline Sign 1 & 4,76 & 0,0961 & 0,0202 & 4,76 & 0,0872 & 0,0204 & 4,28 & 13,342 & 20,116 \\
\hline Sign 2 & 4,80 & 0,0967 & 0,0201 & 4,80 & 0,0879 & 0,0203 & 4,32 & 1,962 & 2,973 \\
\hline Sign 3 & 1,51 & 0,0325 & 0,0216 & 1,51 & 0,0127 & 0,0220 & 0,57 & 1,690 & 2,561 \\
\hline Sign 4 & 6,38 & 0,1246 & 0,0195 & 6,38 & 0,1201 & 0,0196 & 6,12 & 18,987 & 28769 \\
\hline Sign 5 & 1,14 & 0,0248 & 0,0218 & 1,14 & 0,0035 & 0,0222 & 0,16 & 1,179 & 1,787 \\
\hline Sign 6 & 6,84 & 0,1324 & 0,0194 & 6,84 & 0,1290 & 0,0194 & 6,64 & 17,829 & 27,014 \\
\hline Sign 7 & 1,46 & 0,0316 & 0,0216 & 1,46 & 0,0116 & 0,0220 & 0,52 & 1,176 & 1,782 \\
\hline Sign 8 & 1,94 & 0,0415 & 0,0214 & 1,94 & 0,0233 & 0,0218 & 1,07 & 0,058 & 0,088 \\
\hline Sign 9 & 1,94 & 0,0415 & 0,0214 & 1,94 & 0,0233 & 0,0218 & 1,07 & 0,058 & 0,088 \\
\hline Sign 10 & 2,85 & 0,0597 & 0,0210 & 2,85 & 0,0448 & 0,0213 & 2,10 & 0,471 & 0,714 \\
\hline Sign 11 & 1,98 & 0,0424 & & 1,98 & 0,0 & & 1,12 & 0,249 & 0,378 \\
\hline Sign 12 & 4,71 & 0,0938 & 0,0199 & 4,71 & 0,0848 & 0,0201 & 4,22 & 1,576 & 2,388 \\
\hline Sign 13 & 1,35 & 0,0288 & 0,0213 & 1,35 & 0,0087 & 0,0218 & 0,40 & 0,355 & 0,538 \\
\hline Sign 14 & 1,42 & 0,0302 & 0,0213 & 1,42 & 0,0103 & 0,0218 & 0,48 & 0,385 & 0,583 \\
\hline
\end{tabular}

${ }^{1}$ Indicators: $F_{o p}$ - the experimental value of the Fisher criterion; $F_{05}$ - the tabular value of the Fisher criterion at a $5 \%$ significance level $\left(\mathrm{F}_{05}=2.13\right) ; \mathrm{F}_{01}$ - the tabular value of the Fisher criterion at a $1 \%$ significance level $\left(\mathrm{F}_{05}=2.87\right) ; \mathrm{h}^{2}$ - the share of the influence of the organized factor; $\pm \mathrm{sh}^{2}$ - the error of the share of the influence of the organized factor; $\mathrm{Fh}_{h}{ }^{2}$ - the Fisher criterion in assessing the reliability of the share of the influence of the organized factor; $\mathrm{NCP}_{05}$ - the smallest significant difference at a $5 \%$ significance level; $\mathrm{D}_{05}$ - the Tukey criterion is at a $5 \%$ significance level; signs according to previously accepted designations.

At the same time, in most of the signs (signs 3, 5, 7, etc.), the significance of the differences between the variants of light-transforming materials, the significance of the differences has not been confirmed. In variants with confirmed significance of differences, the analysis of variance confidently refutes the null hypothesis that there are no differences between the variants of rooting cuttings using different categories of modified covering material of vegetation structures (see Table 5). This made it possible to continue its implementation on such grounds in terms of calculating estimates of the share of the influence of an organized factor (in our case, the specifics of the regenerative ability of biological samples due to the influence of a particular shelter on them) on the formation of a general phenotypic variance.

In calculations using the Plokhinsky algorithm, estimates ranged from $5.97 \pm 2.10 \%\left(\mathrm{~F}_{\mathrm{h} 2}\right.$ $=2.85 ; \mathrm{F}_{05} / \mathrm{ol}_{1}=2.13 / 2.87$ ) in terms of balanced development of root systems (sign 10) to $12.46 \pm 1.95 \%\left(\mathrm{~F}_{\mathrm{h}}{ }^{2}=6.38 ; \mathrm{F}_{05 / 01}=2.13 / 2.87\right)$ in terms of the total length of root systems (sign 4) and 13.24 $\pm 1.94 \%\left(\mathrm{~F}_{\mathrm{h}}{ }^{2}=6.84 ; \mathrm{F}_{05 / 01}=2.13 / 2.87\right)$ in terms of the total length of lateral roots (sign 6). The calculation of the same values using the Snedekor algorithm gave quite comparable estimates. It can be stated that there is a tendency in the increase of regeneration activity and the processes of root system growth and development of the aboveground part of Hungarian lilac cuttings occurring after it against the background of an increase in the amount of luminophore in the covering material. 


\section{Conclusions}

Agrotextile covering materials containing organic photoluminophore emitting in the red spectral range cause an increase in the activity of callusogenesis and rhizogenesis, as well as an increase in the rate of post-regenerative development of root systems and the aboveground part of stem cuttings of Hungarian lilac. An increase in the concentration of photoluminophore in the covering material of summer vegetation structures leads to an increase in the regenerative ability of summer stem cuttings of Hungarian lilac.

\section{Acknowledgements}

The authors are grateful to D.O. Balakirev (Enikolopov Institute of Synthetic Polymeric Materials, of the Russian Academy of Sciences) for the production and provision of PLcontaining agrotextile for experiments. The work was financially supported by Ministry of Science and Higher Education of Russian Federation [the State Assignments Numbers 07500381-21-00] with the partial financial support from the Russian Foundation for Basic Research [Grant Number 18-29-17073].

\section{References}

1. J.B. Scarratt, For. Chron. 61(4) (1985)

2. V.P. Besschetnov, E.Zh. Kentbaev, Russian Forestry journal, 4 (2018)

3. C. Edser, Plast. addit. compd. 4(3) (2002)

4. R.P. Brown, Rapra Rev. Rep. 15(2) (2004)

5. R. N. Khramov, V. D. Kreslavski, E. A. Svidchenko, N. M. Surin, A. A. Kosobryukhov, Opt. Express. 27(22) (2019)

6. M.A.K. Jansen, Physiol Plant.116, 3 (2002)

7. M.L. Delprato, J. Photochem. Photobiol. 91(5) (2015)

8. Y. Guo, J. Tan, J. Photochem. Photobiol. 91(1) (2015)

9. A. Losi, C. Mandalari, W. Gärtner, J. Photochem. Photobiol. 91(5) (2015)

10. S. Wierdak Acta Soc. Bot. Pol. 1(2) (1923)

11. Yu. N. Luponosov, A. N. Solodukhin, D.O. Balakirev, N. M. Surin, E. A. Svidchenko, S. A. Pisarev, Yu. V. Fedorov, S. A. Ponomarenko, Dyes and Pigments 179, 108397 (2020)

12. Yu. N. Luponosov, A. N. Solodukhin, A. L. Mannanov, P. S. Savchenko, B. A. L. Raul, N. M. Surin, S. M. Peregudova, A. V. Bakirov, M. A. Shcherbina, S. N. Chvalun, M. S. Pshenichnikov, D. Yu. Paraschuk, S. A. Ponomarenko, Materials Today Energy. 22, 100863 (2021)

13. J.H. Zar, Biostatistical Analysis: Fifth Edition. Edinburg Gate: Pearson New International edition - Pearson Education Limited, 756 (2014)

14. A. Dean, D. Voss, D. Draguljić, Design and Analysis of Experiments (Springer Texts in Statistics). 2nd Edition, Kindle Edition. Heidelberg, Germany: Springer-Verlag GmbH. 865 (2017)

15. F. Noll, For. Chron. 86(5) (2010)

16. N.N. Besschetnova, V. P. Besschetnov, Vavilov Journal of Genetics and Breeding. 21(2) (2017) 
17. N.N. Besschetnova, V.P. Besschetnov, A.V. Kul'kova, I.V. Mishukova, Russian Forestry journal, 4 (2017)

18. N.N. Besschetnova, V.P. Besschetnov, P.V. Ershov, Russian Forestry Journal, 1 (2019)

19. V.P. Besschetnov, N.N. Besschetnova, A.O. Esichev, Russian Forestry journal, 1 (2018)

20. A.V. Kul'kova, N.N.Besschetnova, V.P.Besschetnov, Russian Forestry Journal, 6 (2018)

21. M.M. Ulitin, V.P. Besschetnov, Russian Forestry Journal, 6 (2020) 